\title{
THE EFFECT OF IMPLANT LOCATIONS ON THE STRESS TRANSMITTED TO IMPLANT- TOOTH-ASSISTED PARTIAL OVERDENTURE (IN VITRO STUDY)
}

\author{
Tahany M. Kadeeb ${ }^{1 *} B D S$, Sherif M. El Dakkak ${ }^{2} P h D$, Moustafa Abo Shelib ${ }^{3} P h D$, Ahmed A. \\ Abdel Hakim ${ }^{4} \mathrm{PhD}$
}

\begin{abstract}
INTRODUCTION: Posterior free end edentulous areas are more prevalent among population. Absence of posterior abutments to support and retain partial dentures affects the prognosis of prostheses. A problem of support, retention and stability is usually associated with distal extension removable partial dentures.

OBJECTIVES: To evaluate and compare the effect of implant locations on the retention of the prostheses of implant tooth assisted partial overdenture for mandibular Kennedy class II with implant located in first premolar area and second molar area. Second objective was to evaluate the wear of female parts of the attachments attached to these implants.

MATERIALS AND METHODS: The study was conducted on two parallel groups according to the different implant locations: Group (A) implant in first premolar area, Group (B) implant in second molar area. Two acrylic models with Kennedy class II were used in this study. Two implants with (2.3mm length and 3.6mm width), two positioner attachments were attached to implants and inserted in the previous locations for both groups. Each group had 9 sets of attachments with 3 different colored plastic matrices (27 matrices) with different retention force. A metallic overdenture with acrylic resin base and teeth was constructed for each group. By using the universal testing machine, vertical load dislodgment forces were measured at anterior of the saddle of the denture and posterior of the saddle of the denture for both groups at the beginning of the study (initial retention) and after 50,000 cyclic with load of $20 \mathrm{~K}$ at first molar area, the retention test was repeated and the mean value was recorded. All retention parts were imaged under stereomicroscope to study wear and attrition of internal components. All data from both groups in this in-vitro study was gathered, tabulated and statistically analyzed.

RESULTS: In vertical dislodging, Group (B) posterior of the saddle, recorded the highest retention force. In Group (B) anterior of the saddle recorded the lowest retention force. After 50,000 cyclic loading, Group (B) posterior of the saddle was higher than Group (A) in retention force. Dimensional changes and wear scratches appeared in the metal housing and plastic matrices in central and outer lines.

CONCLUSIONS: The distal position of the implant with positioner attachment has great retention during vertical dislodgment compared with mesial implant location with positioner attachment.
\end{abstract}

KEYWORDS: Mandibular class II, implant location, retention, wear.

1- Bachelor of Dentistry, Faculty of Dentistry, October 6 University, Egypt.

2- Lecturer of Prosthodontics, Faculty of Dentistry, Alexandria University, Egypt.

3- Associate Professor of Dental Biomaterials, Faculty of Dentistry, Alexandria University, Egypt.

4- Professor of Prosthodontics, Faculty of Dentistry, Alexandria University, Egypt.

*Corresponding author

E-mail:Tmkadeeb@yahoo.com

\section{INTRODUCTION}

Distal-extension removable partial dentures (RPDs) are associated with several problems related to their stability, retention, esthetics, and masticatory efficiency.

The distal extension removable partial denture is subjected to vertical and horizontal forces that may become adverse during functional and para functional activities. These forces, which can affect denture stability and support are often compensated for some extent by framework and denture base design variations (1).

The distal extension removable partial denture has been implicated in the increase in mobility and destruction of the primary abutment teeth (2). Furthermore, loss of fit, deficiency of function and the resorption of the residual ridge below free-end saddles and wear of the denture teeth, may result in a destabilization of the occlusion (3).

The implant locations depend primarily on the dimensions of the residual ridge and biomechanical consideration of the RPD design. Theoretically, the implants should be located as distally as possible to provide maximal support and stability. This approach converts the edentulous defect from a distal -extension partial Kennedy
Class II situation to the more biomechanically favorable bounded Kennedy Class III $(4,5)$.

Many clinical cases have been reported that the implant could be placed mesial to the edentulous ridge to anchor an implant tissue-supported removable partial overdenture for good esthetic and functional results. The implants may also be placed where adequate bone is available to avoid further surgery (6).

Positioner attachment is a type of stud attachment. It is considered as resilient retainer with different degrees of retention according to the component used. It consists of male and female parts. The female part is screwed to the implant fixture (6).

The male component is made of rubber and is present in the fitting surface of the overdenture incorporated in a metal housing. This rubber part can be changed when subjected to wear (7).

Retention is considered to be the force that resists withdrawal along the path of insertion and stabilizes the overdenture during function. 
An ideal attachment system should provide a high and stable retentive force with a low lateral force to the implant, not only in the parallel placement of the implant, but also in the implant inclination during recurrent dislodging. In fact, a higher retentive force was consistently associated with a higher lateral force.

Positioner abutments do not seem to wear after fatigue tests simulating 5 years of denture insertion and removal. Only minimal changes in the inner diameter of the metal housing of the plastic inserts are induced by simulated wear (8).

The objective of this study was to evaluat the retention of the prosthesis with different implant locations and image the wear of the parts of the attachments.

\section{MATERIALS AND METHODS}

\section{Materials}

The materials that have been used in this study were:

- Two dental mandibular Kennedy class II acrylic models with missing premolars and molars.

- Dental implants: Two implants (Dentium, Seoul, Korea). Two positioner attachments (2.3mm length and $3.6 \mathrm{~mm}$ width) (Dentium, Seoul, Korea).

The following equipments were used in this study:

- Universal testing machine. (Model: 942D10-20, Comten industries, Florida, USA).

- Stereomicroscope (Model SZ1145TR, Olympus, Japan).

A total 18 sets of attachments with 3 different retention colored matrices (54 matrices) were used in this study for both groups. The groups were divided as:

Group (A): Acrylic resin model Kennedy class II with implant located in first premolar area with positioner attachment attached to it.

Group (B): Acrylic resin Kennedy class II with implant in second molar area with a positioner attachment attached to it.

\section{Fabrication of the mandibular acrylic resin model}

Commercially available mandibular models with acrylic teeth were used (Nissin Dental Products, Inc, Kyoto, Japan). This model contained anatomically shaped teeth with roots which can be inserted and removed from the model. The 1st and 2nd premolars and molars were removed from the model unilaterally and their root sockets were blocked with wax (Cavex Set up Regular modeling Wax, Holland BV, Haarlem, Netherlands). Duplication of the modified cast was made using silicon rubber base impression material (Speedex, Coltene Ag, Alsatten, Switzerland). The canine tooth was removed from the model and its root was covered with light body silicone rubber impression to simulate the periodontal ligaments. Then placed in the impression and the impression was poured in acrylic resin.

A soft liner (Softliner, Promedica, GmbH, Neum "unster, Germany) was placed on the residual ridge to simulate the mucosa.

\section{Implant placement}

Two parallel drill holes were drilled in the models in first premolar location in Group A and in second molar region in Group B with a hand piece. Drilling was performed starting with the pilot drill $(2.3 \mathrm{~mm})$ in diameter then intermediate drill $(2.6 \mathrm{~mm})$ in diameter was used and driven to the full depth of the planned implant, and finally with $(3.6 \mathrm{~mm})$ in diameter.

\section{Construction of removable partial denture}

Two removable partial dentures (metallic framework and acrylic resin base and teeth) were constructed.One RPD for each model. The metal framework design relied on canine cingulum rest with double akers clasps fabricated on first and second premolars on the other side for cross arch stabilization. Lingual bar was the major connector for this design. Teeth with metallic backing were fabricated in the first premolar in Group (A) and in the second molar in Group (B). The dentures were flasked, acrylic resin teeth were set and facing of the metallic backing teeth were made and heat cured denture base resin was then packed and polymerized. Finishing and polishing of the denture were made.

Two positioner attachments were assembled on the inserted implants. The positioner attachment was inserted with manufacturer instructions and selection of the ring depended on the difference of the retention of each type as: the orange color equals the retention of (500GF) representing maximum retention while the ivory one is (300GF) and the white is for the extra -light retention (100 GF). There were different retention for each color as coded in the manufacturer instructions. (GF: meaning Gram Force). Metal housing was fixed in the fitting surface of the metallic teeth backing.

Nine sets of retention rings were used for each group (n = 9), each comprising the three levels of retentive elements (rings) (i.e. 27 nylon inserts for each group).

A total of 54 nylon inserts were used in this study Retention test (dislodging tests):

In this test some modifications were made in the denture and the model to be compatible with the hook:

- Two holes were made by round bur in the denture posterior and anterior to the saddle for easy attachment of the hook to the denture by a non-deformable wire.

One metal hook was attached to the occlusal surface of each experimental overdenture in the anterior and posterior of the saddle of denture's regions. This hook attached to a universal testing machine to measure the load required to dislodge an attachment. The crosshead speed was 50 $\mathrm{mm} / \mathrm{min}$.

- A hole was constructed at the base of the cast. This hole was used for fixation of the test model to the base of the testing machine. The occlusal plane of the model was set even with the horizontal plane of the metal base of the testing machine. To account for the weight of the experimental overdentures, the machine was calibrated and balanced.

The testing machine was used to apply vertically oriented tensile loads until the attachments separated from the abutments. Minimum loads needed to dislodge the overdenture from the test model (retentive force) were calculated (Fig.1).
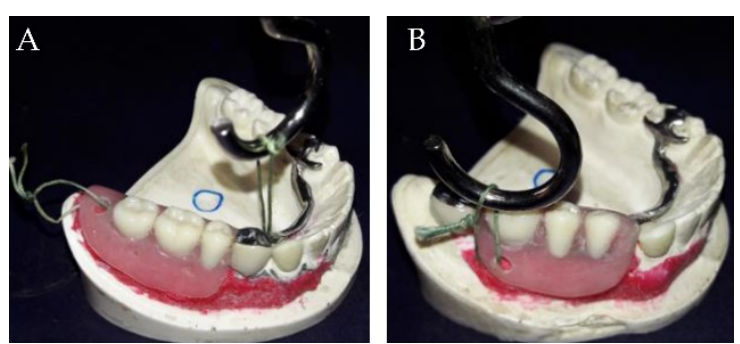

Figure (1): (A) showing the hook attached in anterior saddle of the denture of Group (A) case. (B) The hook holding the posterior saddle of the denture of Group (B) case. 
Vertical dislodgement was performed with the hook in the anterior and posterior of the saddle of denture regions. Five measurements were performed for each of the two types of groups.

The hook was attached to the anterior wire of the denture of Group (A) first to measure the anterior retention and the results recorded. The test repeated five times to gain the mean for this force. The hook was attached to the posterior wire of the denture of Group (A) to measure the posterior retention and the test was repeated to record the mean for this force. The test was repeated in the same way to the anterior and posterior holes of the saddle for Group (B).

The test was also repeated with different type of matrices with different retention potentials; The white ring $100 \mathrm{GF}$, the ivory $300 \mathrm{GF}$ and the orange $500 \mathrm{GF}$.

After 50,000 cyclic with load $20 \mathrm{~K}$ at the first molar area, to simulate repeated insertions and removals of the overdenture over 277-month period (assuming six daily removals and insertions of the overdenture for the purpose of hygiene) the test started for both groups in the same previous technique for the accuracy of the results. The loadto dislodgment was recorded when full separation of the overdenture from the base unit occurred. All 54 attachments were tested and their average recorded.

\section{Wear test}

Retentive component was sectioned along the center. These components were: the metal housing, the nylon patrix index with different colors and the positioner attachments.

1. Two implant analog were attached to two positioner attachments. They all installed in clear self-cured acrylic resin for easy cutting later. Fig. (2.A)

2. Plastic attachment parts were removed from the metal rings. And the matrices were cut with sharp blade along their longitudinal axes. Fig. (2.B).
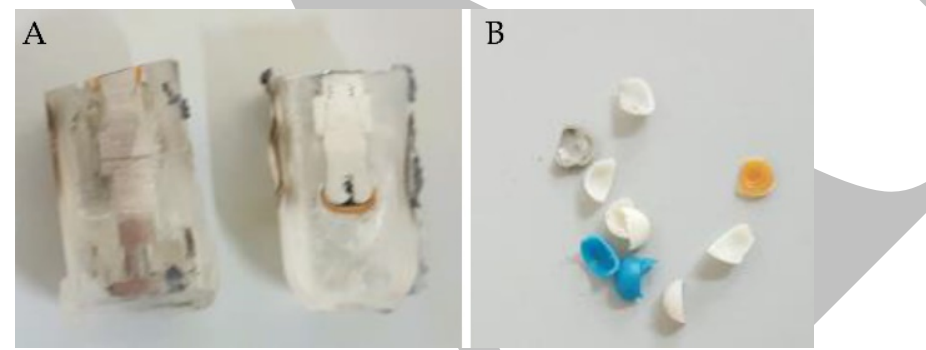

Figure (2): (A) showing the implant analog with positioner attachment, metal housing and orange ring in clear acrylic, (B) showing the cut plastic matrices.

All 54 Positioner plastic inserts testing embedded in their corresponding Overdenture units were photographed using a digital camera (OLYMPUS, E-330, Olympus Optical Co.Ltd., Tokyo, Japan) coupled to a stereomicroscope (OLYMPUS Stereomicroscope SZII, Olympus optical Co.Ltd.2-43, Tokyo, Japan) at 18× magnification Biomaterials Department, Faculty of Dentistry, Alexandria University.

The captured photographs were loaded on Cell-A Imaging software (V.3.2) Olympus soft imaging Solution $\mathrm{GmbH}$, Munstar, Germany) that was used to measure the difference in thickness between matrices.

\section{Statistical analysis:}

Data were fed to the computer and analyzed using IBM SPSS software package version 14.0 (SPSS Inc., Chicago, IL, USA) (statistical package for social science). Descriptive statistics were used to calculate means and standard deviations for the maximum retentive force. Twoway ANOVA was used to compare recorded vertical retention values between different implant positions (Group A, Group B) and location of measurement (anterior of saddle, posterior of saddle) (Multivariate analysis). The level of statistical significance was set at $\mathrm{p}<0.05$.

\section{RESULTS}

\section{Results of retention test}

In Table (1) and Fig. (3), the means between groups were statistically significant $(p<.001)$ for all groups. The highest mean of retention was in the posterior of the saddle of Group (B) with mean 674.7000 with standard deviation 242.The lowest mean of retention was recorded in the anterior saddle of the Group (B) 29.1000 with standard deviation 2.806.

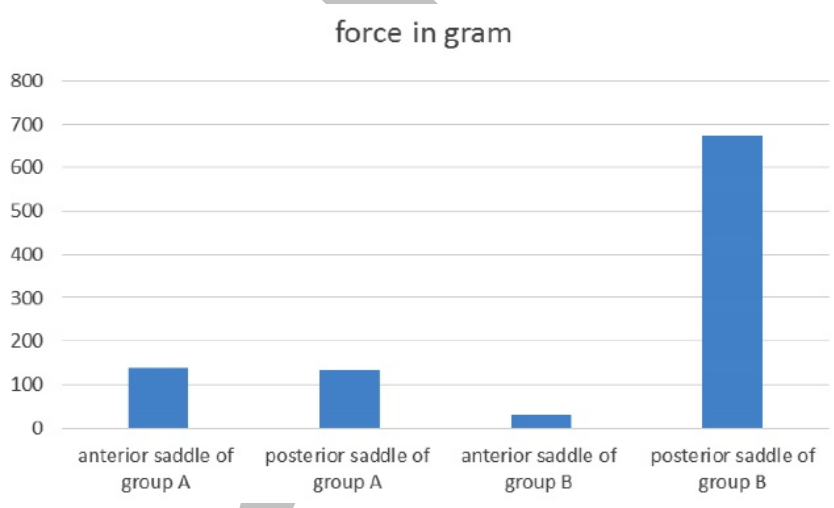

Figure (3): Showing comparison between the mean values of retention test in gram for the two studied groups.

In Table (1) fig (4), after 50.000 cyclic loading the means between two groups showed that the greatest mean value of retention force was found in the posterior saddle of posterior implant position Group (B) was 285.3000 SD+91.846. The lowest mean was resulted for the anterior saddle of the Group (B) 22.1000, SD+- 2.3309. There were significant reductions in the retention of the prosthesis with implant in mesial area compared with distal implant location.

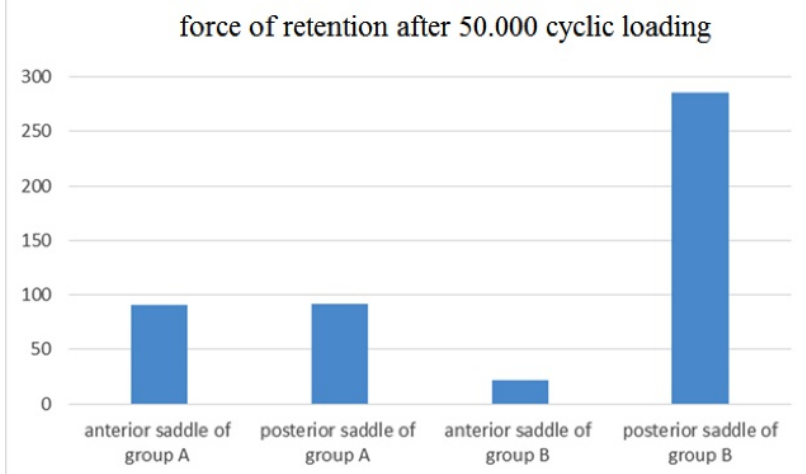

Figure (4): Showing the mean values of retention in gram after 50,000 cyclic loading between both groups. 
Table (1): Showing comparison between the mean values of the mean of retention force test in gram for the two studied groups (A, B), before and after 50,000 cyclic loading.

\begin{tabular}{|c|c|c|c|c|c|}
\hline & $\begin{array}{l}\text { Implant } \\
\text { Position }\end{array}$ & $\begin{array}{c}\text { location of } \\
\text { measurements }\end{array}$ & Mena & $\begin{array}{c}\text { Std, } \\
\text { Deviation }\end{array}$ & $\mathbf{N}$ \\
\hline $\begin{array}{r}\text { Force } \\
\text { in } \mathrm{g}\end{array}$ & $\begin{array}{c}\text { Group } \\
\text { A } \\
\text { Group } \\
\text { B } \\
\text { Total }\end{array}$ & $\begin{array}{c}\text { Anterior saddle } \\
\text { Posterior saddle } \\
\text { Total } \\
\text { Anterior saddle } \\
\text { Posterior saddle } \\
\text { Total } \\
\text { Anterior saddle } \\
\text { Posterior saddle } \\
\text { Total }\end{array}$ & $\begin{array}{c}137.000 \\
134.7000 \\
135.8500 \\
29.1000 \\
674.7000 \\
351.9000 \\
83.0500 \\
4040.7000 \\
243.8750\end{array}$ & $\begin{array}{c}5.03322 \\
8.83239 \\
7.09540 \\
2.80674 \\
241.88797 \\
370.67902 \\
55.49346 \\
323.24752 \\
280.95024\end{array}$ & $\begin{array}{l}10 \\
10 \\
20 \\
10 \\
10 \\
20 \\
20 \\
20 \\
40\end{array}$ \\
\hline $\begin{array}{c}\text { After } \\
50.000 \\
\text { cyclic } \\
\text { loading }\end{array}$ & $\begin{array}{c}\text { Group } \\
\text { A } \\
\begin{array}{c}\text { Group } \\
\text { B }\end{array} \\
\text { Total }\end{array}$ & $\begin{array}{c}\text { Anterior saddle } \\
\text { Posterior saddle } \\
\text { Total } \\
\text { Anterior saddle } \\
\text { Posterior saddle } \\
\text { Total } \\
\text { Anterior saddle } \\
\text { Posterior saddle } \\
\text { Total }\end{array}$ & $\begin{array}{c}90.7000 \\
91.7000 \\
91.2000 \\
22.1000 \\
285.3000 \\
153.7000 \\
56.4000 \\
188.5000 \\
122.4500\end{array}$ & $\begin{array}{c}6.49872 \\
8.02842 \\
7.12741 \\
2.33095 \\
91.84655 \\
149.09238 \\
35.51041 \\
117.85517 \\
108.88360\end{array}$ & $\begin{array}{l}10 \\
10 \\
20 \\
10 \\
10 \\
20 \\
20 \\
20 \\
40\end{array}$ \\
\hline
\end{tabular}

\section{Results of wear test}

The measurements were carried out by using Stereomicroscope with digital camera attached photographing the specimens at $18 \mathrm{x}$ magnification and it showed morphological changes on the inner and outer part of the metal housing and the plastic parts. Dimensional changes of plastic parts and metal housings of attachments were analyzed. Considerable changes were verified in patrix/matrix parts. Wear simulation scratches along the path of insertion were seen on inner surfaces of plastic rings. Particle loss and irregular surface were characteristic changes for Positioner attachment. The positioner attachment was magnified at 1.8 megapixel while the patrix were magnified at 4 to 4.5 megapixel. Fig. (5).
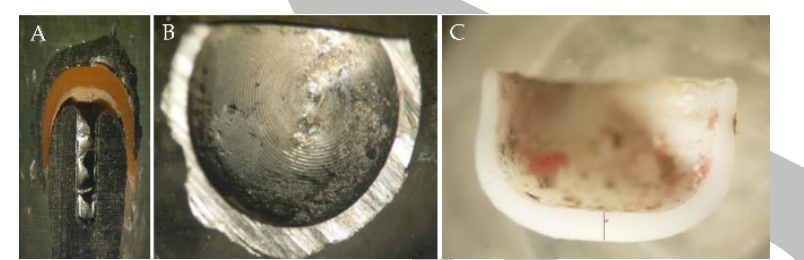

Figure (5): (A) cross section of the attachment with metal housing under stereomicroscope. (B) Showing the metal housing with scratches. (C) Showing the dimensional changes in the ivory retention matrix.

\section{DISCUSSION}

The present in vitro study investigated the effect of implant position on the retention of a simulated prosthesis. In this retention test, a general trend was determined that an increased resistance to dislodgment occurred as the implant location was distally. This result was statistically significant for both groups. In the present study, dislodging forces generally increased as implant was placed in the second molar area. Retention of the denture is a major concern to patients, and one of the greatest challenges that faces clinicians. Studies have not established a consensus regarding what is considered sufficient retention. This study has revealed that implant location play a significant role in prosthesis retention, in agreement with several researches (9-11).
Anterior dislodgment simulates movement that may occur when the patient tries to remove the denture by applying pressure opposite to the attachments anteriorly, during anterior dislodging, the mean values of retention force in Group (A) was higher than Group (B). And after 50,000 cyclic loading the same results was observed also. But the retention value was reduced after the cyclic loading. The decreased retention after cyclic loading may be due to deterioration and wear of the central projection of the inserts more than the outer retentive ring.

Posterior dislodgement is one of the most anticipated movements that occurred clinically when the distal extension base of the mandibular overdenture lifts off the tissues during function $(13,14)$. During posterior dislodging, Group (B) showed the highest retention force before and after cyclic loading. A distal implant position may be advantageous, as it increases denture stability during posterior dislodgement of the denture.

The results of this in vitro study indicate that implants placed at the second molar site may be a more-effective location for implant-retained overdenture therapy compared with the first premolar site. In this test the distal implant reported the highest mean retentive values. This increase in retention was statically significant and could potentially be clinically significant as well. The lowest mean value were reported in the mesial implant location.

Positioner attachments showed a significant reduction in retentive forces after repeated insertions and removals. It is difficult to attribute this reduction to dimensional changes of the inner core or the inner diameter of the inserts, since no significant correlations were found between changes in retentive forces and wear-related measurement changes. An explanation of these unexpected changes in retention could be related to surface deterioration of the insert surface with subsequent increase in surface roughness through micromechanical friction (15). In agreement with this finding, Kleis et al (16) demonstrated that Positioner attachments lost some of their retentive capacity over time as a result of wear of the patrix Positioner parts. Similarly, Turk et al (17) reported that Positioner attachments showed significant retention loss after 50.000 to 300.000 cycles. Among different Positioners retentive types, Positioner light retention type demonstrated the greater retention loss for all dislodging forces. Although this in vitro analysis showed a statistical difference among the groups, long-term comparative prospective controlled studies are needed to reach agreement on an accepted treatment.

Among the widely used stud attachment systems, the positioner attachment uses a dual retention approach combining inner and outer frictional modes and is designed to provide three different retention strengths according to the plastic insert color (18). The frictional retention mechanism relies on the press fit of the central stud of the plastic insert within the inner metal socket of the abutment and the simultaneous engagement of the abutment undercut by the outer margin of the insert (19). Surface wear tends to be more expressed on the central stud than on the outer ring of the plastic insert, because the force was concentrated in the center than on the outer rings. Use of plastic insert allow easy and economic replacement of worn matrix components.

Although in vitro studies differ from clinical studies, they allow standardization of test conditions. The limitations of this study included lack of simulation of in 
vivo conditions regarding the presence of saliva, amount of occlusal force, and power of masticatory muscles, which may affect the wear pattern and retentive values of Positioner inserts (20).

\section{CONCLUSION}

Within limitations of this in vitro study, it could be concluded that:

1-A distally placed implant may be considered preferable in terms of retention to a mesially placed implant as a solution for the problems associated with mandibular distalextension removable partial overdenture.

2-Wear was observed in the female part of the attachment which need to be replaced after repeatable insertion and removal for long time.

\section{CONFLICT OF INTEREST}

The authors declare that they have no conflicts of interest.

\section{ACKNOWLEDGMENTS}

I would like to extend my gratitude to all my family and friends for their great help and support.

\section{REFERENCES}

1-Giffin KM. Solving the distal extension removable partial denture base movement dilemma: a clinical report. J Prosthet Dent. 1996;76:347-9.

2-Bui DX. Removable Partial Denture and its Effects on Periodontal Health. Dinh X. Bui, D.D.S., M.S. Available at: http://www.drbui.com/artrpd.html

3-Germundsson B, Hellman M, Odman P. Effects of rehabilitation with conventional removable partial dentures on oral health--a cross-sectional study. Part II. A comparative study of treatment results at two Public Dental Clinics and the Faculty of Odontology in Gothenburg. Swed Dent J. 1984;9:233-40.

4-Mijiritsky E. implants in conjunction with removable partial denture: A literature review. Implant Dent. 2007;16:146-54.

5-Ohkubo C, Kueihara D, Shimpo Suzuki Y, Kokubo Y, Hosoi T. Effect of implant support on distal extension removable partial dentures: In vitro assessment .J Oral Rehabil. 2007;34:52-6.

6-Chikunov I, Doan P, Vahidi F. Implant retained partial overdenture with resilient attachments. J Prosthodont. 2008;17:141-8.

7-Kurtzman GM. The locator attachment: free standing versus bar-over dentures. Dental Labor Inter Plus. 2009;1:20-3.

8-Rutkunas V, Mizutani H, Takahashi H, Iwasaki N. Wear simulation effects on overdenture stud attachments. Dent Mater J. 2011;30:845-53.
9-Michelinakis G, Barclay CW, Smith PW. The influence of interim plant distance and attachment type on the retention characteristics of mandibular overdentures on 2 implants: Initial retention values. Int J Prosthodont. 2006;19:507-12.

10-Doukas D, Michelinakis G, Smith PW, Barclay CW. The influence of interim plant distance and attachment type on the retention characteristics of mandibular overdentures on 2 implants: 6-month fatigue retention values. Int J Prosthodont. 2008; 21:152-4.

11- Tabatabaian F, Sabouri A, Sobhani Z. Effect of InterImplant Distance on Retention and Stability of Overdenture. 36th Annual Conference of the European Prosthodontic Association, 2012. Sept 6-8, Rotterdam, Netherland. 2012.

12-Rabbani S, Juszczyk AS, Clark RK, Radford DR. Investigation of retentive force reduction and wear of the locator attachment system with different implant angulations. Int J Oral Maxillofac Implants. 2015;30:55663.

13-Stephens GJ, di Vitale N, O'Sullivan E, McDonald A. The influence of interimplant divergence on the retention characteristics of Locator attachments, a laboratory study. J Prosthodont. 2014;23:467-75.

14-Petropoulos VC, Smith W. Maximum dislodging forces of implant overdenture stud attachments. Int $\mathrm{J}$ Oral Maxillofacial Implants. 2002;17:526-35.

15-Tehini G, Baba NZ, Majzoub Z, Nahas P, Berberi A, Rifai K. In Vitro Effect of Mastication on the Retention and Wear of Locator Attachments in a Flat Mandibular Ridge Model. J Prosthodont. 2018.

16-Kleis WK, Kämmerer PW, Hartmann S, Al-Nawas B, Wagner W. A comparison of three different attachment systems for mandibular two-implant overdentures: one-year report. Clin Implant Dent Relat Res. 2010;12:209-18.

17-Türk PE, Geckili O, Türk Y, Günay V, Bilgin T. In vitro comparison of the retentive properties of ball and locator attachments for implant overdentures. Int J Oral Maxillofac Implants. 2014; 29:1106-13.

18-Alsabeeha N, Atieh M, Swain MV, Payne AG. Attachment systems for mandibular single-implant overdentures: an in vitro retention force investigation on different designs. Int $\mathrm{J}$ Prosthodontic. 2010;23:160-6.

19-Sarnat AE. The efficiency of cobalt samarium (Co5Sm) magnets as retention units for overdentures. J Dent. 1983;11:324-33.

20-Evtimovska E, Masri R, Driscoll CF, Romberg E. The change in retentive values of locator attachments and hader clips over time. J Prosthodont. 2009;18:479-83. 